\title{
CARCINOGÊNESE EXPERIMENTAL COM DMBA EM SOLUÇAO
}

José Alberto B. Opitz

Acadêmico da $4^{\text {a }}$ série da Fac. de Odontol. da U.F.R.G.S., Bolsista do Conselho de Pesquisas da U.F.R.G.S.

Coordenador: Hardy Ebling

Professor Titular de Patologia Geral e Bucodental do Departamento 2

\section{SITOPSE}

Inoculon-se em 14 ratos Wistar nma solução de 9-10-dimetil-1-2-benzantraceno (DMBA) em óleo de amendoim, na região pré-auricular. Após um periodo variável entre 70 - 312 dias, observon-se no local da injeção, a formação de tumor de consistência fibrosa, aparentemente localizados, de côr esbranquiçada ao corte. 0 estudo histológico mostrou tratar-se de rabdomiosarcomas.

Com a finalidade de estudar a formação de tumores, injetou-se 9-10dimetil-1-2-benzantraceno (DMBA) na articulação têmporo-mandibular de 14 ratos, de cêrca de 100 gramas de pêso. Como solvente foi usado óleo de amendoim. Os animais foram sacrificados após verificação clínica đo tumor. o material foi examindo e classificado histològicamente.

No estudo dos neoplasmas induzidos em animais de experimentação com agentes químicos carcinogenéticos, várias poderiam ter sido as formas de neoplasmas. Elzay (1), em 1966, utilizou DMBA em álcool e obteve clìnicamente tumores epiteliais precoces maiores do que os hamsters pincelados com DMBA em óleo mineral. Conclui êle que histològicamente os hamsters que combinadas ou coadjuvadas pelo isoproterenol injetado, obtiveram nas primeiras semanas a formação de cisto epidermóide e hiperplasia glandular. Após 10 semanas notou a evidência de carcinoma epidermóide. Camilleri (3) e Smith, em 1964, obtiveram papilomas e carcinomas pincelando em hamsters, 3 vêzes por

R. Fac, Odont. P.A.

12: $77-82, \quad 1970$ 
semana, DMBA a $0,5 \%$, solução em liquido parafina (B.P.).

\section{MATERIAIS E MÉTODOS}

Foi utilizado 9-10-dimetil-1-2benzantraceno em óleo de amendoim refinado, seringa tipo Luer de 5cc. e injetados em ratos Wistar. Foi escolhida a região pré-auricular por se tratar de uma região rica na variedade de tecidos e, ao que parece, não haver estudos dêsse tipo nesta área. Foram selecionados 9 ratos para sercm injetados no lado direito e 5 ratos no lado esquerdo. Foi injetado apenas uma gêta da substância.

\section{RESULTADOS}

Os animais foram sacrificados, um aos 70 dias, um aos 181 dias, quatro aos 196 dias, um aos 229 e um aos 312 dias, todos com um tumor. Os seis animais restantes foram sacrificados posteriormente, aparentemente sem tumor. Os tumores apresentavam consistência fibrosa, eram aparentemente localizados e fixos às estruturas vizinhas. Seu tamanho variou de $2 \mathrm{~mm}$ a cêrca de $1 \mathrm{~cm}$ de diâmetro, e sua loca- lização coincidia com $o$ ponto de aplicação da droga. Não apresentavam dificuldade ao corte e eram de côr esbranquiçada. Os ratos foram necropsiados $€$ os tumores fotografados e submetidos a técnica histológica de rotina. $\mathrm{O}$ exame histológico mostrou tratar-se de rabdomiosarcoma.

\section{DISCUSSA0}

Por se tratar de um tumor bastante raro, lâminas foram coloridas pela $H$. ácida fosfotúngstica, método tricrômico de Malleri e Van Gieson, mostrando êstes métodos que na verdade o tumor era um rabdo. miosarcoma.

\section{SYNOPSIS}

Forteen Wistar rats were used for innoculation of 9-10-dimethyl-1-2benzantracene (DMBA) in solution, in the pre-auricular region to study tumor's formation. During a period of 70 to 312 days, tumors of fibrous consistency and apparently localized were observed. They showed whitishness at the cut. Histologically they were classified as Rhabdomyosarcoma. 


\section{REFERENCIAS BIBLIOGRAFICAS}

1 - ELZAY, R. P. Local effect of alcohol in combination with DMBA on hamster cheeck pouch. J. Dent. Res, Chicago, 45: 1788-95, nov.-dec., 1966.

2 - SHKLAR, Gerald \& CATALDO, Edmundo. D efeito do isoproteronolna carcinogênese do DMBA em glândulas submaxilares de ratos. J. Dent. Res., Chicago, 43: 893, suppl sept.-oct. 1964.

3 - CAMILleRIA, G. E. \& SMITH, C. J. Carcinogênese oral experimental; investigação prematura da lesão por citologia expoliativa. J. Dent. Res., Chicago, 43: 966, suppl. sept.-oct. 1964. 


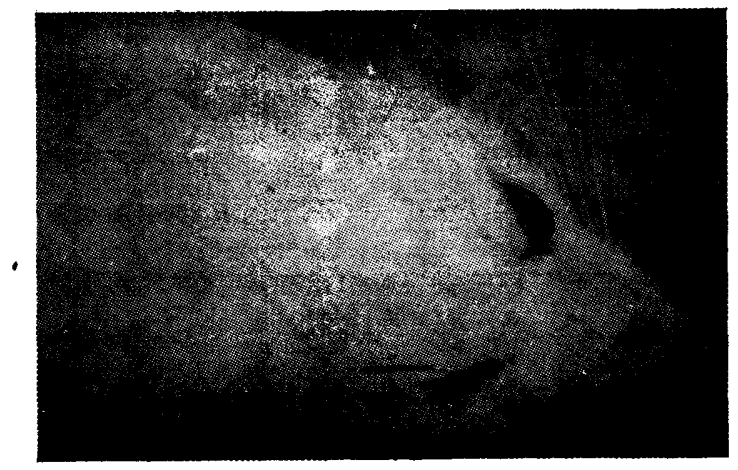

Fig. 1

Aspecto clínico d a lesão, notando-se a exoftalmia no lado lesado.

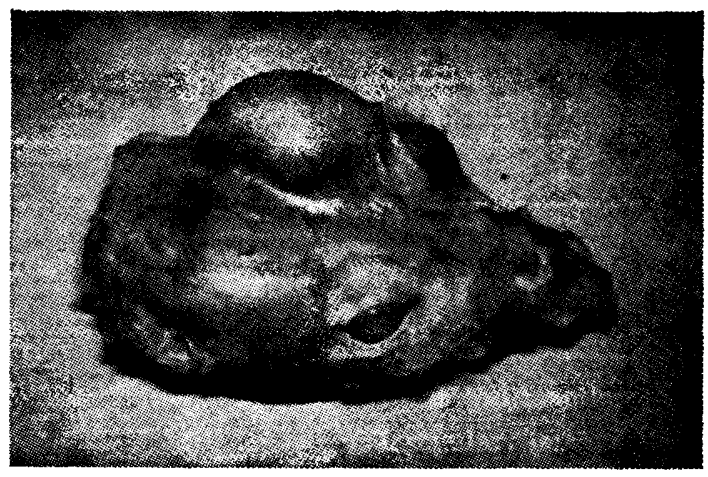

Fig. 2

Rato dissecado, visão de campo.

R. Fac. Odont. P.A. 


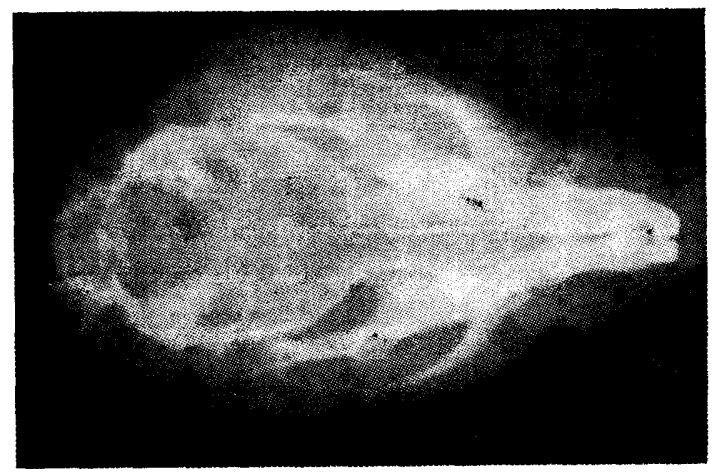

Fig. 3

Aspecto radiográfico da lesão, notando-se a fratura patológica do arco zigomático.

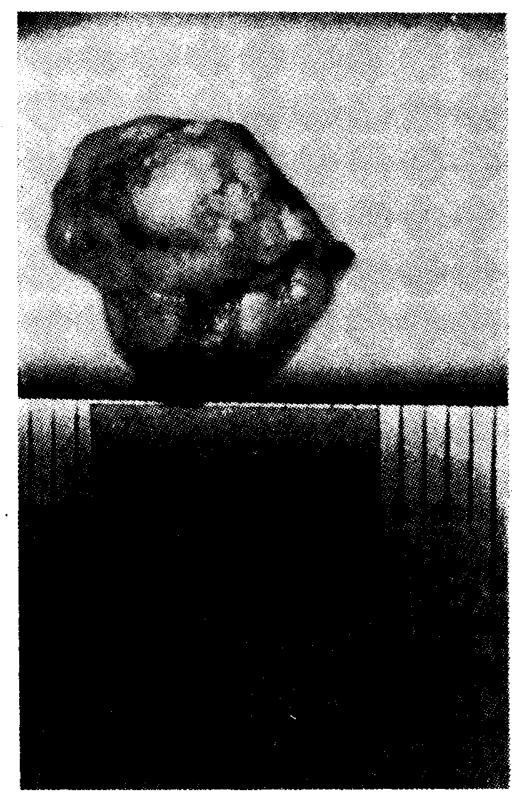

Fig. 4

Aspecto macroscópico da peça.

R. Fac. Odont. P.A. 


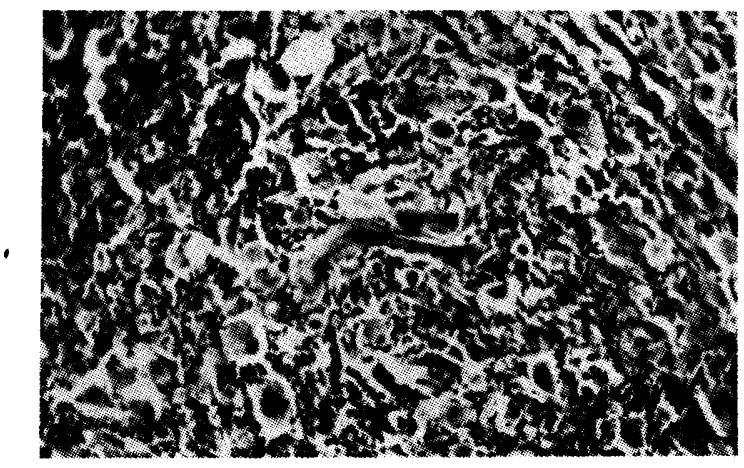

Fig. 5

Aspecto microscópico da peça.

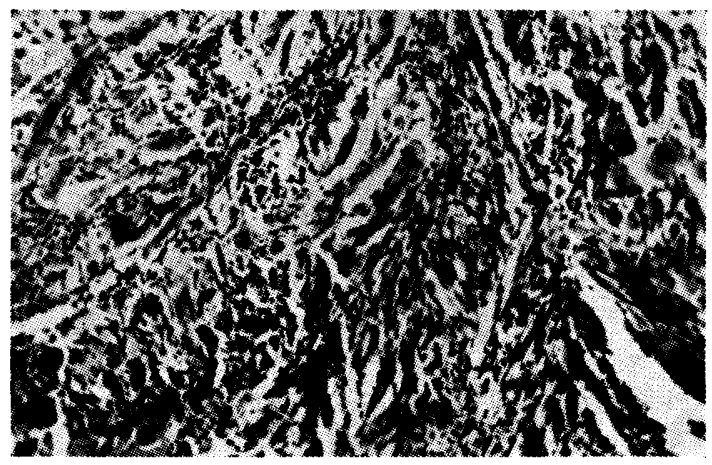

Fig. 6

Aspecto microscópico da peça.

R. Fac. Odont. P.A.

12: $77-82, \quad 19.70$ 